\title{
Tensile Properties of Pandanus Atrocarpus based Composites
}

\author{
Hoo Tien Nicholas Kuan ${ }^{1}$, Meng Chuen Lee ${ }^{2}$ \\ ${ }^{1,2}$ Mechanical and Manufacturing Engineering, Universiti Malaysia Sarawak, Kota \\ Samarahan, Malaysia. \\ ${ }^{1}$ Email: khtnicholas@feng.unimas.my,2Email:maxchuen90@yahool.com
}

\begin{abstract}
Pandanus atrocarpus, or locally known as mengkuang plant is likely to be potential natural fibre reinforcement in composite. Both the Pandanus leaves, and fibres extracted from the Pandanus leaves were used in composite fabrication. Fibres were extracted from Pandanus leaves with water retting process. Pandanus composites were laminated using compression moulding method. The tensile properties of composite laminates based on lamination of Pandanus leaf- and extracted Pandanus fibre-reinforced polyethylene were investigated. Tensile tests have shown that composite laminates based on extracted Pandanus fibre reinforced polyethylene were more superior than using the Pandanus leaf itself without extracting its fibre. Tests exhibited that increasing the volume fraction of Pandanus fibre resulted in strength increase. This suggests that Pandanus fibre- based composites could offer a range of mechanical properties for use in the engineering industry.
\end{abstract}

Keywords: Pandanus atrocarpus, natural fibre, tensile, polyethylene.

\section{Introduction}

The year 2009 has been appointed by the United Nations to be the international year of natural fibres. This indicates the significant of the usage of natural fibres in the history of human development. Natural fibres have long been utilised since the ancient world. People used natural fibres to meet their basic necessity, such as in textiles, clothing, housing appliances and building materials. The usage of green fibres depends on the quantities of local production or natural resources of the location. Natural fibres were used in ancient Egypt some 3000 years ago, when clay was reinforced by straw to build walls [1]. Kvavadze et al. [2] have also reported that man used flax fibres in prehistoric times for weaving baskets and sewing garments in caves in Georgia more than 30,000 years ago.

The usage of natural fibres can be found widely in a variety of industries, such as in automotive, aerospace, building, plastic and textile. One of the noticeable applications of natural fibres is to replace synthetic fibres or man-made fibres as reinforcement in the composite production. There has also been an increasing interest in the use of polymer fibre composites reinforced natural fibres. Polymer composites have widely been applied due to the benefits they possess, such as light, cheap and ease of fabrication. Natural fibres have less environmental impact compare to synthetic fibres. The biodegradable natural fibres are economic viability, low density, enhance energy recovery, ease of separation, reduce dermal and respiratory irritation, good specific strengths and modulus [3-5]. Research and studies done on natural fibres used as reinforcement in composite has shown promising results [6-7]. The aim of the work presented here is to investigate the possibility of using Pandanus atrocarpus reinforced thermoplastics polyethylene to produce a lightweight composite panel. The composites were manufactured by using both Pandanus leaves, and fibres extracted from Pandanus

Manuscript History:

Received 26 September, 2014, Revised 27 September, 2014, Accepted 29 September, 2014, Published 30 September, 2014

e-ISSN 2289-7771

Copyright $\odot 2014$ JASPE 
leaves as reinforcement of polyethylene. The two types of composites are compressed moulded at elevated temperature. Particular attention is given to characterising the tensile properties of these composite structures.

\section{Methods and Materials}

The natural fibres used in this study were the Pandanus atrocarpus, or the local mengkuang leaves. The plants are grown abundantly and wildly in moist and swampy areas in Sarawak. Two types of composites were investigated in this study. The first composite was fabricated using Pandanus leaves itself as reinforcement to polyethylene. The Pandanus leaves were dried in the sun for approximately two weeks before they were used. The leaves were pressed with approximately 100 $\mathrm{kg}$ of heavy object while drying to produce flat leaves in order to ease the composite fabrication. The second type of composite was fabricated using the fibres extracted from Pandanus leaves. Water retting was used to extract fibres from the leaves. The leaves were submerged in distilled water tank for approximately two weeks. The outer layers of the leaves were peeled off to extract the internal fibres before they were dried in the sun for approximately two days. Once the extracted fibres were dried, they were used as reinforcement to polyethylene to fabricate composite structures.

Seven different types of laminates were manufactured in this study and details of the stacking sequences of the laminates are given in Table 1. All of the composite laminates were compression moulded in a hydraulic press machine. Laminate A was based on 25PE/25PE, a total of 50 plies of neat polyethylene (PE) film and heating the stack to approximately $160^{\circ} \mathrm{C}$. Laminates $\mathrm{B}$ to $\mathrm{D}$ were manufactured by stacking a layer of Pandanus leaf in between 40, 50 and 60 plies of polyethylene films, respectively. Laminate $\mathrm{E}$ was produced by using $18 \mathrm{~g}$ of short random fibres (approximately 3 $\mathrm{cm}$ ) with 50 plies of polyethylene film. Laminates $\mathrm{F}$ and $\mathrm{G}$ were produced by incorporating two different weights of long unidirectional fibres (18 g and $28 \mathrm{~g}, 230 \mathrm{~mm}$ in length) with 50 plies of polyethylene film, respectively. Laminates $B$ to $G$ were manufactured by heating the composites to approximately $180^{\circ} \mathrm{C}$ before cooling to room temperature. Tensile tests were then conducted on a Shimadzu universal testing machine at a crosshead displacement rate of $10 \mathrm{~mm} /$ minute for all the laminates. Tensile samples were cut to a width of approximately $25 \mathrm{~mm}$ and a length of $230 \mathrm{~mm}$ for tensile testing.

Table 1. Summary of the laminates investigated in this study

\begin{tabular}{|c|c|c|}
\hline Laminate & Constituent Materials & Stacking Sequence \\
\hline $\mathrm{A}$ & 50 plies neat polyethylene $(\mathrm{PE})$ & 25PE/25PE \\
\hline $\mathrm{B}$ & 20 plies PE +1 layer of PA leaf +20 plies PE & $20 \mathrm{PE} / 1 \mathrm{PA} / 20 \mathrm{PE}$ \\
\hline $\mathrm{C}$ & 25 plies PE +1 layer of PA leaf +25 plies PE & $25 \mathrm{PE} / 1 \mathrm{PA} / 25 \mathrm{PE}$ \\
\hline $\mathrm{D}$ & 30 plies PE +1 layer of PA leaf +30 plies PE & $30 \mathrm{PE} / 1 \mathrm{PA} / 30 \mathrm{PE}$ \\
\hline $\mathrm{E}$ & 25 plies PE $+18 \mathrm{~g}$ PA fibres $($ Random $)+25$ plies PE & $25 \mathrm{PE} / 18 \mathrm{gPA}(\mathrm{R}) / 25 \mathrm{PE}$ \\
\hline $\mathrm{F}$ & 25 plies PE $+18 \mathrm{~g}$ PA fibres (Unidirectional $)+25$ plies PE & $25 \mathrm{PE} / 18 \mathrm{gPA}(\mathrm{U}) / 25 \mathrm{PE}$ \\
\hline $\mathrm{G}$ & 25 plies PE $+28 \mathrm{~g}$ PA fibres (Unidirectional $)+25$ plies PE & $25 \mathrm{PE} / 28 \mathrm{gPA}(\mathrm{U}) / 25 \mathrm{PE}$ \\
\hline
\end{tabular}




\section{Results and Discussion}

Figure 1 shows the stress-strain curves following tensile tests on the one layer Pandanus atrocarpus leaf reinforced polyethylene composites at a crosshead displacement rate of $10 \mathrm{~min} / \mathrm{mm}$. Laminate A, neat polyethylene is included for comparison in the figure. Laminate A exhibits a nonlinear response with the stiffness decreasing with increasing strain. Localised plasticity takes place between the fibres with the loading direction, and thus leading to a knee in the stress-strain curve. The stiffness then remains approximately the same until the laminate fails in a ductile manner at a strain of $22 \%$. The tensile strength obtained is approximately $11 \mathrm{~N} / \mathrm{mm}^{2}$. The Pandanus leaves reinforced polyethylene composites exhibits better tensile strength in excess of $14 \mathrm{~N} / \mathrm{mm}^{2}$. From the figure, it can be seen that reinforced one layer of Pandanus leaf will increase the strength of the laminate. Increasing the volume fraction of polyethylene in the laminates increases the tensile strength of Laminate D to approximately $23 \mathrm{~N} / \mathrm{mm}^{2}$. An examination of the failed Pandanus reinforced polyethylene composite samples highlighted a delamination fracture of the crack, with Pandanus leaf separated from polyethylene before tensile fracture.

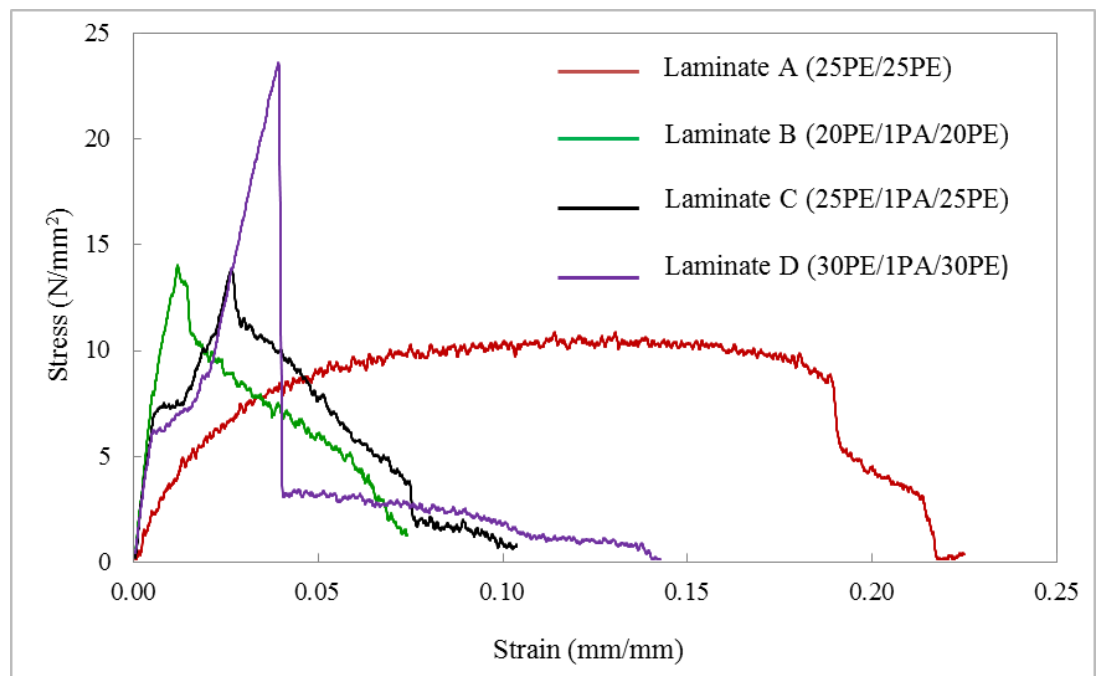

Figure 1. Stress-strain curves following tensile tests at a crosshead displacement rate of $10 \mathrm{~mm} / \mathrm{min}$ for the one layer PA leaf reinforced PE (40,50 and 60 plies of PE). Laminate A (neat PE) is included for comparison.

Figure 2 shows the typical stress-strain traces following tensile tests at a crosshead displacement rate of $10 \mathrm{~mm} / \mathrm{min}$ of the laminates based on extracted Pandanus fibres reinforced polyethylene. During the initial stages of the loading, all the laminates exhibit a more brittle response but offers tensile strength that exceed $18 \mathrm{~N} / \mathrm{mm}^{2}$ that are all better than the laminate manufactured with Pandanus leaf as in Figure 1. Laminate E manufactured with short random Pandanus fibres (approximately $3 \mathrm{~cm}$ ) reinforced polyethylene composite exhibit a strength of approximately 19 $\mathrm{N} / \mathrm{mm}^{2}$. Using long and unidirectional Pandanus fibres reinforced polyethylene (Laminates $\mathrm{F}$ and $\mathrm{G}$ ) offers a better tensile strength compare to the short random fibre (Laminate E). Laminate E exhibits a lower tensile strength as the load was dissipated in multi-direction by the randomly oriented short fibres. The short fibres were unable to bear as much stress as the longitudinal aligned fibres [8]. The tensile strength for Laminate $F$ and Laminate $G$ are approximately $39 \mathrm{~N} / \mathrm{mm}^{2}$ and $44 \mathrm{~N} / \mathrm{mm}^{2}$, respectively. Increasing the volume fraction of Pandanus fibres to approximately $4 \%$ (Laminate $\mathrm{G}$ ) in the composite will increase about $13 \%$ of the tensile strength of the laminate. An investigation of the fractured Pandanus fibres reinforced polyethylene samples showed a highly fibrous fracture with strands and groups of fibres extending away from the crack (Figure 3). 


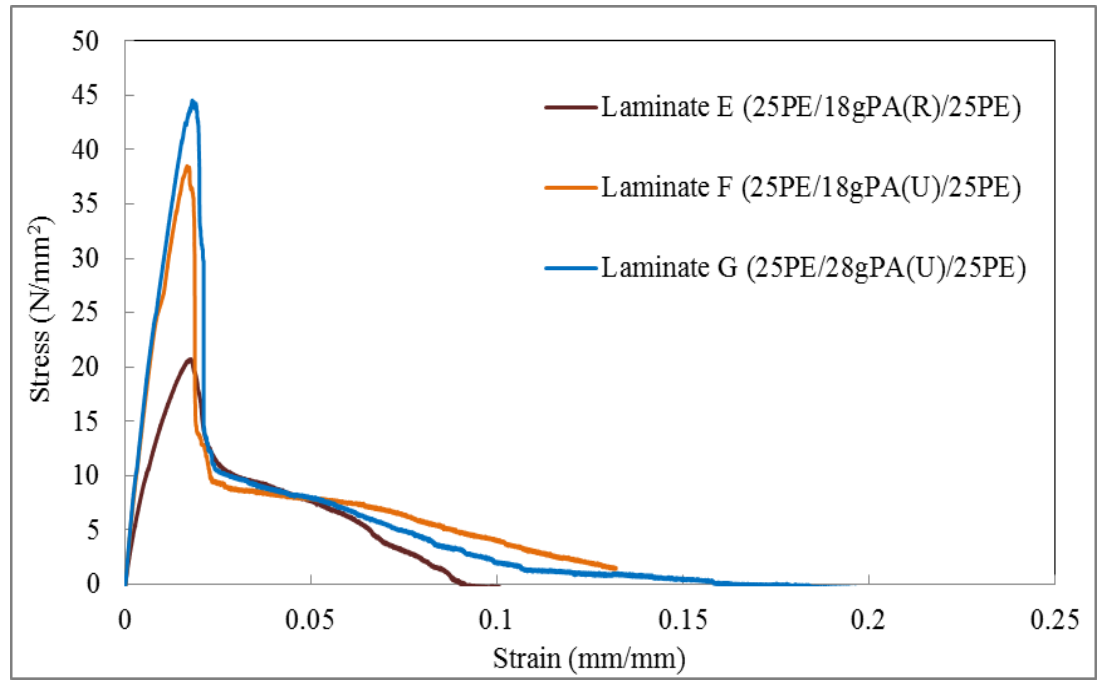

Figure 2. Stress-strain curves following tensile tests at a crosshead displacement rate of $10 \mathrm{~mm} / \mathrm{min}$ for the PA fibres (random and unidirectional) reinforced PE.

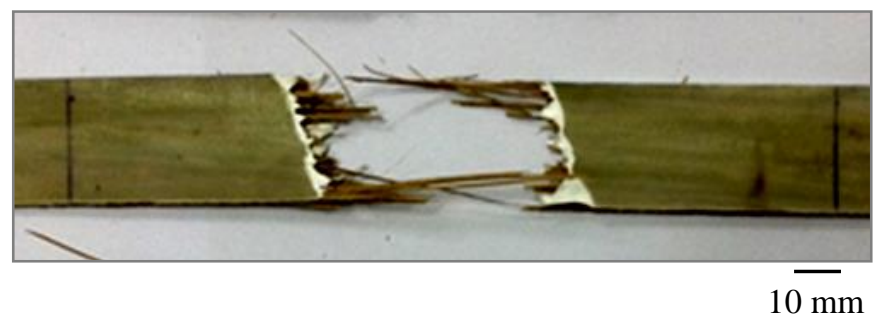

Figure 3. Tensile sample Pandanus fibres reinforced polyethylene composite (Laminate D).

The variation of the tensile strength of all the Pandanus (leaf and fibre) reinforced polyethylene composite are shown in Figure 4. Laminate A (neat PE) is included for comparison. Clearly the tensile strength for both the Pandanus leaves (Laminate B to D), and fibres reinforced polyethylene composites (Laminates E to $\mathrm{G}$ ) are higher than the neat polyethylene laminate (Laminate A). Using extracted fibres in composite laminating exhibits a better strength than using the leaf itself. The epidermises of the Pandanus leaves weakened the interlamination bonding between the reinforcement and polyethylene matrix, and thus resulted in weaker strength for Laminate B to D. The beneficial of introducing extracted Pandanus fibres had led to approximately three-fold increase in tensile strength, from approximately $14 \mathrm{~N} / \mathrm{mm}^{2}$ (Laminate C) to $39 \mathrm{~N} / \mathrm{mm}^{2}$ (Laminate F). It is evident that increasing the volume fraction of Pandanus fibres increases the tensile strength of the laminate. 


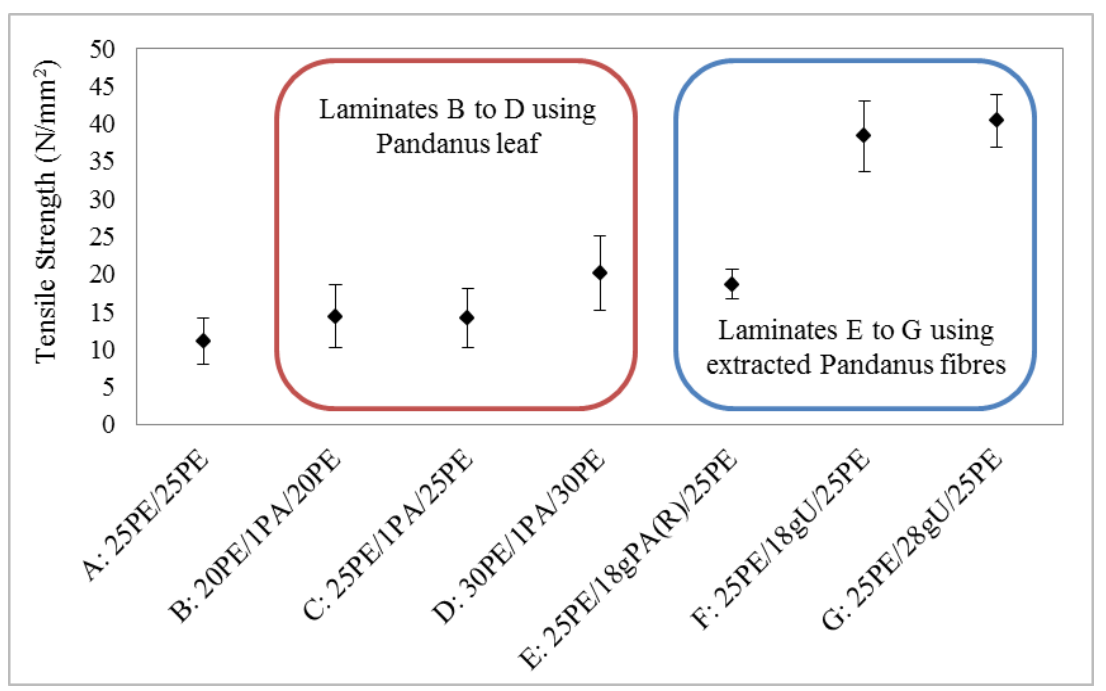

Figure 3. The variation of the tensile strength of the entire PA (leaf and fibres) reinforced PE. Laminate A (neat PE) is included for comparison.

\section{Conclusions}

The tensile properties of composites based on Pandanus atrocarpus and polyethylene have been investigated. Tests have exhibited that reinforced Pandanus atrocarpus in the laminate structure will improve the tensile strength of the composite. Tensile testing results also exhibited that introducing extracted Pandanus fibres will lead to a higher strength in the laminates than reinforcing with Pandanus leaf only. Increasing the volume fraction of fibres will increase the strength of the composites. This is a potentially attractive result since improvements in response of the tensile behaviour can be achieved without using the unfriendly synthetic fibre reinforcement.

\section{Acknowledgements}

The authors express gratitude to Universiti Malaysia Sarawak for providing the opportunity and supports to conduct this research, and to MOHE in funding the project through FRGS grant (FRGS/TK04(01)/1081/2013(27)), and OGFICE grant.

\section{References}

[1] W. D. Brouwer, (2000). Natural Fibre Composites in Structural Components: Alternative Applications for Sisal, Proceedings of a Seminar held by the Food and Agriculture Organization of the UN (FAO) and the Common Fund for Commodities (CFC), Rome.

[2] E. Kvavadze, O. Bar-Yosef, A. Belfer-Cohen, E. Boaretto, N. Jakeli, Z. Matskevich, T. Meshveliani. (2009). 30,000 Year Old Wild Flax Fibers Science, Vol. 325, No. 5946, 1359.

[3] J. W. Lawton , G. F. Fanta, (1994). Glycerol-plasticitized films prepared from starch- poly(vinyl alcohol) mixtures: effect of poly(ethylene-co-acrylic acis), Carbohydrate Polymers, Vol. 23, No. 4, 1, 275.

[4] S. V. Joshi, L. T. Drzal, A. K. Mohanty, S. Arora, (2004), Are natural fiber composites environmentally superior to glass fiber reinforced composites?, Composites: Part A, Vol. 35, No. 3, 371.

[5] A. Chauhan, B. S. Kaith, A. S. Singha, D. Pathania, (2010). Induction of the morphological changes in Hibiscus sabdariffa on graft copolymerization with acrylonitrile and co-vinyl monomers in binary mixture, Malaysia Polymer Journal, Vol. 5, No. 2, 140-150. 
[6] H. T. N. Kuan, W. J. Cantwell, Md. Akil Hazizan, C. Santulli, (2011). The Fracture Properties of Environmental-Friendly Fiber Metal Laminates, Journal of Reinforced Plastics and Composites, Vol 30, No. 6, 499-508.

[7] D. Nabi Saheb, J. P. Jog, (1999). Natural Fiber Polymer Composites: A Review, Advances in Polymer technology, Vol.18, No.4, 351-363.

[8] D. Hull, T. W. Clyne, (1996). An Introduction to Composite Materials, Cambridge University Press.

\section{Authors}

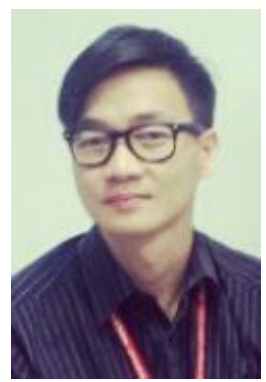

\section{Hoo Tien Nicholas Kuan}

Hoo Tien Nicholas Kuan is a senior lecturer, attached to the Department of Mechanical and Manufacturing Engineering, Faculty of Engineering, Universiti Malaysia Sarawak (UNIMAS). He received his PhD (Engineering) in 2011. His field of interest are green materials and composite engineering

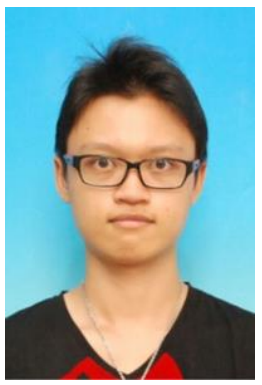

\section{Meng Chuen Lee}

Meng Chuen Lee is a postgraduate master research engineering student at the Universiti Malaysia Sarawak (UNIMAS). He received his BEng (Hons) (Mechanical and Manufacturing Engineering) in 2014. 